\title{
Anadili Türkçe olan öğrenenlerde Rusçadaki vurgunun yanlış yazımından kaynaklı öğrenme hataları ${ }^{1}$
}

Zeynep BAKAL2

\begin{abstract}
APA: Bakal, Z . (2018). Anadili Türkçe olan öğrenenlerde Rusçadaki vurgunun yanlış yazımından kaynaklı öğrenme hataları. RumeliDE Dil ve Edebiyat Araştırmaları Dergisi, (13), 196-206. DOI: 10.29000/rumelide.504942
\end{abstract}

$\ddot{\mathbf{O z}}$

$\mathrm{Bu}$ çalışmanın amacı, ana dili Türkçe olan ve farklı bir alfabede yazma deneyimi edinmemiş öğrenenlerin Rusçadaki vurgunun yazımını yanlış öğrenmeleri sonucu ortaya çıkan hatalara dikkat çekmektir. Bu çalışma üç eğitim-öğretim dönemi boyunca 632 öğrencinin yazma becerilerinin gözlemlenmesi sonucu ortaya çıkmıştır. Çalışma şu başlıklar altında incelenecektir: Rusçada vurgunun sabit bir yerinin olmaması, köke, öneke, soneke, kaynaştırma harfine, kimi zaman edata ve ismin hal ekine gelebilmesi sonucu ortaya çıkan yazım hataları. Kişi zamirlerine göre fiil çekimlerinde vurgunun yerinin değişmesi sonucu ortaya çıkan yazım hataları ve bunların fonetiğe olan etkileri. Zamanlara göre fiil çekimlerinde vurgunun yerinin değişmesi sonucu ortaya çıkan yazım hataları ve bunların fonetiğe olan etkileri. Sözcüklerden türeyen kelimelerde vurgunun yerinin ana kelimeden farklı yerde olabilmesi sonucu ortaya çıkan yazım hataları. Bir sözcüğü diğerinden ayırt etmede yapılan yazım hataları. Özellikle Türk öğrenenler için harf benzerliklerinin karıştırılması sonucu ortaya çıkan yazım hataları. Tüm bu hatalara bağlı olarak gelişen fonetik hatalar.

Anahtar kelimeler: Rusça, Türk öğrenenler, vurgu, yazım hataları, öğrenme hataları.

\section{Learning erros caused by the faulty use of the stress sign of the Russian language which leads to learning errors made by learners who are native Turkish speakers}

\begin{abstract}
The aim of this study is to paying attention to the errors that arise as a result of the learners' being misunderstood in writing the stress in Russian. This study is the result of observing the writing skills of 632 students during three education-teaching periods. The study will be examined under the following headings: In Russian, the stress doesn't have a fixed place; it could drop to the root or prefix or suffix, the letter of inclusion, or prepositions. Sometimes it could drop to suffix of cases. This kind of errors causes writing and phonetic errors. Spelling errors resulting from the displacement of the stress in verb conjugation according to pronouns and their effects on phonetics. Spelling errors resulting from the displacement of the stress in verb conjugation according to the times and their effects on phonetics. In sentences derived from words, the location of the stress can be different than the main word. This may result in spelling errors. Spelling mistakes in distinguishing one word from another. Spelling errors, especially for Turkish learners as a result of mixing letters similarities. Phonetic errors due to all these errors.
\end{abstract}

Part of this paper was presented as an oral presentation at Düzce University International Conference on Language (DUICOL / WRITING - 2018) held on 18-20 October, 2018.

2 Öğr. Gör., İstanbul Okan Üniversitesi, İnsan ve Toplum Bilimleri Fakültesi, Mütercim Tercümanlık Bölümü, Rusça Mütercim Tercümanlık Bölümü, (İstanbul, Türkiye), zeynep.bakal@okan.edu.tr, ORCID ID: 00oo-0002-7487-0864 [Makale kayıt tarihi: 30.10.2018-kabul tarihi: 22.12.2018; DOI: 10.29000/rumelide.504942] 
Key words: Russian, Turkish learners, stress, spelling mistakes, learning mistakes.

\section{Giriş}

Bu çalışmada anadili Türkçe olan öğrenenlerin Rusça yazmada vurguyu öğrenirken yaşadığı zorlukların neler olduğunu ve bunların ortaya çıkış nedenlerini görerek bu zorlukların nasıl giderilebileceğine dair bazı öneriler bulabilirsiniz. Bu çalışmayı 3 eğitim-öğretim dönemi boyunca, seçmeli derslerine girdiğim mühendislik, mimarlık, lojistik, pilotaj, uluslararası ilişkiler, hukuk fakültelerinin 527, Turizm Rusçası derslerine girdiğim, Turizm ve Otel İşletmeciliği bölümünün 35, İkinci yabancı dil olarak Rusça derslerine girdiğim, İngilizce ve Çince Mütercim Tercümanlık bölümlerinin 70 öğrencisini gözlemleyerek yaptım. Mütercim tercümanlık öğrencileri seçmeli gruplarda bulunan öğrencilerden farklı olarak bu dili ikinci yabancı dil olarak almakta A1 seviyesi geçildikten sonra ders yükleri artmaktadır. Söz konusu 632 öğrencinin \%9o ‘ 1 haftada 4 saat A1 seviyesi, \%10’u ise haftada 6 saat A1 seviyesi ders almış öğrencilerden oluşmaktadır.

Ülkemizde Rusça eğitimi, fakültelerin Dil-Edebiyat ya da Çeviribilim bölümlerinde, fakültelerde seçmeli ders olarak, bazı özel okullarda ilköğretim seviyesinde ve dershanelerde verilmektedir. Öğretmenler dili öğretmeye alfabe öğretimi ile başlamakta, bu iki basamakta gerçekleşmektedir; kitap harfleriyle okuma ve yazma, el yazısı ile yazma ve okuma. Yazma kısmında el yazısı alfabeye ek olarak gelen vurgunun yazımının öğretiminde Türk öğrenenler çeşitli anlama ve uygulama zorlukları yaşamakta, hatalara düşmekte, bu yazım hataları fonetik ve gramer hatalarını tetiklemektedir.

Öğrenci 33 harften oluşan Kiril alfabesini basılı kaynaktan okumaya çalışırken, kitap harflerinden \%75 farklı olan el yazısı harflerle de yazmayı öğrenmek durumundadır. Buna ek bir işaret olarak gelen vurgu, ilk dersi alfabe olan öğrenenlerde kafa karışıklığına yol açmaktadır.

\section{Yöntem}

Çalışmam deneysel bir çalışma olmayıp, söz konusu 632 öğrencinin derste, ders dışı etkinliklerde ve sınavlarındaki yazma becerilerini gözlemleyerek ulaştı̆̆ım sonuçlar üzerine kurulmuştur.

Çalışmamda sırasıyla; öğrencilerin kiril alfabesini öğrenme, yazma, vurguyu öğrenme, yazma ve doğru olarak okumasına bakılmıştır.

Kiril alfabesinin öğretilmesi, iki aşamadan oluşmakta olup; kitap harflerinin öğretilmesi, ardından el yazısının öğretilmesi biçimindedir. Söz konusu öğrencilere ilk derslerinde kitap harfiyle okuma ve yazma öğretilmiş, vurgu bilgisinden bahsedilmemiş, ikinci derslerinde el yazısı harflere geçilmiş ve yine vurgu bilsinden bahsedilmemiştir. Bu derse kadar öğrencilere okuma bilgisi verilmemiş, öğrencilerin sadece kiril alfabesine ait harfleri ve bu harflerin seslerini tanımaları istenmiştir. Öğrenciler bir sonraki derslerinde vurgu bilgisiyle ilk defa karşılaşmış ve ilk defa harflerden kelimeler üretip okur duruma gelmişlerdir. Yeni bir alfabeyi doğru okuma ve yazma bilgisi bütünleşik olarak verilmiştir. Vurgunun işlevi ve fonetiğe olan etkisi ile ilk kez karşılaşan öğrencilere el yazısı pratiğini geliştirmeleri adına el alıştırmaları verilmiştir. Bu alıştırmalar, 'O' harfinin ve 'E' harfinin ses değişimini fonetik transkripsiyonlar üzerinden gösteren alıştırmalar olup, toplamda 4'er saatlik birer çalışmayı gerektirmektedirler. Bu alıştırmalara gereken süreyi harcayan (yaklaşık \%20) öğrencilerin konuyu kavrama başarısının, gerekli süreyi harcamayanlara oranla daha yüksek olduğu, yazımda vurguyu başka bir harfle karıştırma oranlarının (yaklaşık \%10) daha düşük olduğu, fonetik hatalara daha az düştükleri (yaklaşık \%20) gözlemlenmiştir. Ders içi etkinliklere katılan, ancak verilen görevi tamamlamamış 
Learning erros caused by the faulty use of the stress sign of the Russian language which leads to learning errors made by learners who are native Turkish speakers / Z. Bakal (p. 196-206)

öğrencilerde başarı oranının birinci gruba göre yaklaşık \% 15 oranında daha düşük olduğu, bu öğrencilerin alıştırmalarla desteklenmedikleri sürece başarı oranlarının giderek düştüğü gözlemlenmiştir. Vurgunun öğretimi, yazma ve okuma çalışmasıyla birlikte verildiğinden öğrencilere ders içinde dinleme çalışması yaptırılmış, ders içi etkinliklerde sunulan bu sesli materyallere odaklanan öğrencilerin, vurgunun yazımında yine hatalara düştükleri ancak ilginç bir şekilde fonetik hatalarını en aza indirdikleri gözlemlenmiştir.

Vurgu bilgisinin toplam dört ders saatine yayılan bu kısa anlatımı, ders saatleri içinde verilen görevlerin sağlıklı bir şekilde tamamlanamaması, ev ödevlerinin konunun tam anlaşılması için yeterli süreye ulaşmadan verilmiş olması; öğrencinin konuyu tam kavramamış olmasından kaynaklı hatalara düşmesine, daha önceden çok fazla ödev ve yazma pratiği geliştirmemiş öğrencilerin ödevlerini yeterince kontrol etmemesine ve bunun sonucunda hataların tesbit edememesine, hataların tesbitinin sinif ortamına bırakılmasına, dolayısıyla bireysel hataların gözden kaçmasına neden olmuştur. Bu çalışmada öğrencilerin yaptı̆̆ı genel ve ağırlıklı hatalara odaklanılmıştır.

\section{Vurgunun yazımının öğretilme amacı}

Rusçanın yabancı bir dil olarak öğretiminde vurgunun yeri, önemi ya da karşılaşılan zorluklarla ilgili Rus kuramcıların çeşitli çalışmaları mevcuttur. "Rusçadaki padej (ismin hal ekleri) sisteminin, Rusçadaki zamanların ya da hareket filllerinin öğretilmesinden önce öğrenci, yeri değişen bir vurgu ile savaşmak zorundadır.” (Беженарь О.А.)

Öğrenciler ikinci bir dili öğrenirken kimi zaman kendi anadillerinden farklı bir alfabeyi öğrenmek durumunda kalırlar. Farklı bir alfabeyle dil öğrenen öğrenci ise bunu kendi el yazısı pratiği ile geliştirmek durumunda kalacaktır. Rusçayı ikinci dil olarak öğrenenler için de durum aynıdır. El yazısı harfleri öğrenmek ve yazmak durumunda olan öğrenci vurguyu da beraberinde yazmayı öğrenir. El yazısı kullanımında bahsedilen kaligrafi olmamakla birlikte öğrencilerin akıcı ve anlaşılır bir yazı kullanmalarına yönelik bir eğitim verilmektedir. Bu süre 112 saatlik toplam eğitim süresinin \%3’ü kadardır. Bu sürenin sonunda vurgu bilgisi verilir ve artık öğrencilerden kelimeleri vurgusu ile yazmaları beklenir. Vurgunun yazımının öğretilmesi fonetik ve gramer kaygılardan ötürüdür diyebiliriz.

Rusçada vurgunun, iki işlevi olduğunu biliyoruz. Bunlardan biri vurgulu hecenin uzun, güçlü ve net okunması, ikincisi ise vurgusuz hecedeki sesli harflerin değişime uğramasıdır.

Sesli harfler olan У, И, Ы seslerinin uzayarak değişmesi; sesli harfler olan О, Е, Я ve Э’ nin ise foneminin değişmesi söz konusudur. Bunu aşağıdaki tabloda izlersek;

\begin{tabular}{|l|l|}
\hline \multicolumn{2}{|l|}{ Tek sesli harfler } \\
\hline Vurgulu & Vurgusuz \\
\hline О АЕ Э Я & А и и и \\
\hline
\end{tabular}

Sirasıyla bakacak olursak öğrenciler, fonem bilgisini, sözcükte vurgunun yerini ve el yazısını birlikte öğrenirler.

\section{Vurgunun öğretimi sırasında karşımıza çıkan hatalar}


Vurgunun yazımını öğretirken karşılaşılan hataları şu başlıklar altında sıralayabiliriz:

1. Alfabeden kaynaklı sorunlar:

Vurguyla gelen sorunlara tek tek bakacak olursak ilk sırada alfabenin kendisinden kaynaklı iki nokta dikkatimizi çeker. Bunlar «Й» ve «Ë» harflerinin yazımının vurguyla karıştırılmasından kaynaklı hatalardır.

a. «Й\ ünsüz bir sestir. Ancak harfin adının «Kısa i» olması ve yazımında, üzerinde kendi çizgisinin bulunması, yazımı yanlış öğrenildiğinde vurgu ile karıştırılabilmesine yol açmaktadır. Bu durumda öğrenci:

\section{Kisaltma İşareti}

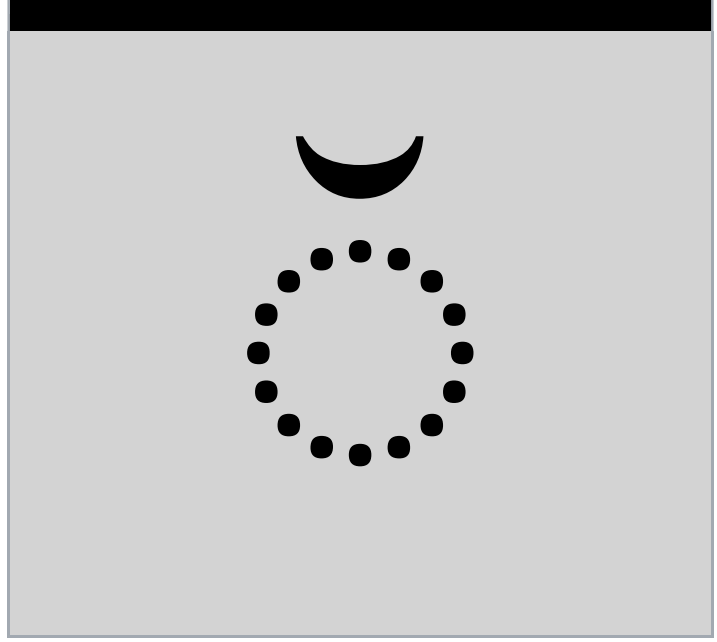

yerine

\section{Vurgu İşareti}

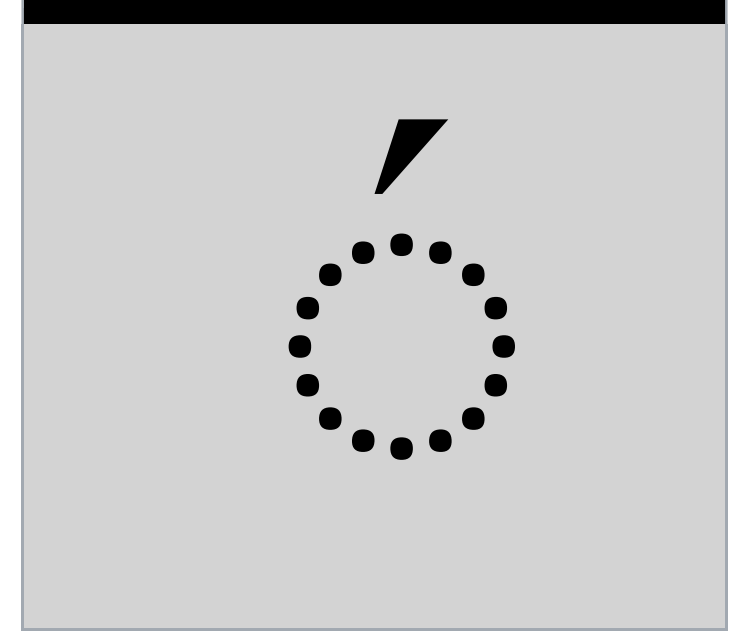

yazacaktır. 
Learning erros caused by the faulty use of the stress sign of the Russian language which leads to learning errors made by learners who are native Turkish speakers / Z. Bakal (p. 196-206)

«Й» sesinin yazımının yanlış öğrenilmesinin nedenlerinden biri de, öğrencilerin yazma sırasında özensiz davranmaları ve harfin üzerinde yer alan kısaltma çizgisi yerine vurgu işaretini kullanmaları sonra da bunu vurgunun kendisiyle karıştırmalarıdır.

Aynı kelime içinde "Ру' сский" kelimesinde olduğu gibi sesli bir harf olan "И" harfi de bulunabileceğinden öğrenci vurguyu yanlış öğrenmişse kelimeyi kısaltabilmekte, başkalaştırabilmekte ve sonucunda da yanlış okumaktadır. Burada karşımıza harfin yazımının vurguyla karıştırılması sonucu fonetik bir hata çlkar. Vurgunun yanlış öğrenimi yüzünden harfi başkalaştıran ve kelimeyi değiştiren öğrenci bu defa da kelime çekim eki aldığında, bir gramer hatasına sürüklenmiş olur.

b. «ت̈ » harfi kendinden vurgulu bir harftir dolayısıyla vurgunun kendisi ile karıştırılması çok olasıdır. Bundan kaynaklı hatalarda öğrenci;

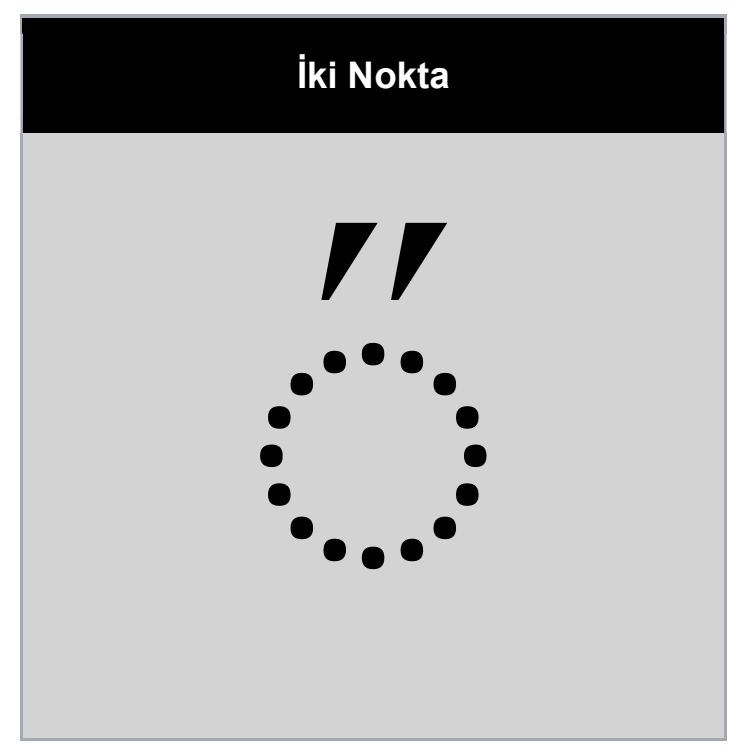

yerine yine,

\section{Vurgu İşareti}

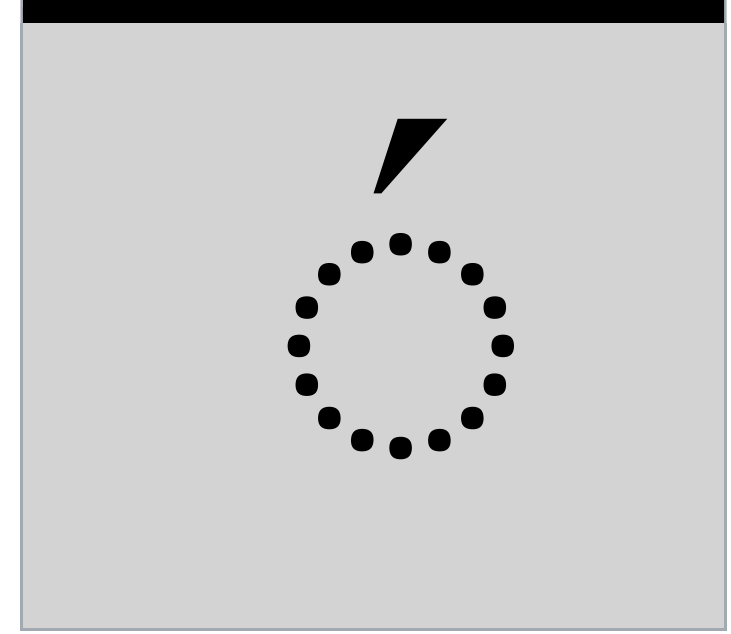


getirmek suretiyle hataya düşmektedir. Burada yine öğrencinin yazarken özensiz davrandığını görüyoruz. Ancak buradaki özensizlik bir fonetik hataya yol açmaz. Çünkü öğrenci harfi her türlü doğru okuyacaktır. Buradaki öğrenim hatası, aynı kelime içinde vurgusuz «E» harfinin de bulunması durumunda, vurgunun «苂» harfine mi yoksa «E» harfine mi getirileceği, öğrencinin aradaki farkı ayırt edememesi ve kelimeyi yanlış öğrenip, yanlış okumasıdır.

Bu durumdan kaynaklı hataların \%35 civarında olduğu gözlemlenmiştir. Aynı şekilde bu hatayı ortadan kaldırmak için, yazma alıştırmasının fonetik çalışmalarla desteklenmesi gerektiği gözlemlenmiştir.

2. Fonetik sorunlar;

Bu sorunun iki parçası bulunmaktadır; ses değişikliği ve tonlama.

a. Türk öğrenenler için Rusçada vurgunun yazımının öğrenilmesi ve bunun doğru kullanımı, vurgunun fonetik olarak öğrenilmesinden daha zor bir konudur.

Her dilde olduğu gibi Türkçede de kelimelerin vurgu ile ayrımı söz konusu iken;

\section{ORdu - orDU, KURtuluş- KurtuLUŞ, GİTme- GitME}

gibi anlam farklılığı yaratan fonetik ayrımlar olsa da, yazımda bir farklılık olmadığından öğrenenlerin bu konuya odaklanmaları zor olmaktadır. Bunun nedeni öğrencinin vurguyu sadece bir ses vurgusu olarak algılaması ama neden olduğu fonem değişikliklerine ilk etapta odaklanamamasıdır.

b. Fonetik hatalara başka bir örnek de vurgunun yanlış öğrenilmesinden kaynaklı isimlerin cinsinin karıştırılması sorunudur.

\section{Фо' то}

Yukarıdaki örnek kelimede vurgu doğru konabilmiş ancak okuma çalışması sonrasında, kelimenin cinsiyetinin yanlış tespit edildiği gözlemlenmiştir. Burada yazma ya da okuma hatası bulunmamakta ancak vurgudan gelen fonetik değişiklik, yazma alıştırmasıyla öğretilmiş bir gramer kuralının kullanımında kafa karışıklığı yaratmaktadır. Burada vurgudan kaynaklı ses değişiminin gramer kuralına aktarılırken yazma becerisi ile karıştırıldığını gözlemliyoruz ki bu durum başlı başına ayrı bir araştırma konusu olabilmektedir.

Bu nötr cins kelimeye bir örnektir ve Rus kuramcıların (Т.М Балыхина.) en çok üzerinde durduğu konudur. Bu cinsin çoğullarında vurgunun yeri mutlaka değişmektedir. Aşağıdaki tablo bu değişimi, ismin hallerinin tekil ve çoğul durumlarına göre göstermektedir. Yanlış öğrenme sonucu özellikle bu tür kelimelerde öğrencinin ismin yalın durumunun çoğuluyla tamlayan durumunun tekil halini karıştırdığı gözlemlenmiştir. 


\begin{tabular}{|lll|}
\hline İsmin Durum ekleri & Tekil & Çoğul \\
Yalın durum & окно' & о' кна \\
Tamlayan Durumu & окна' & о' кон \\
Yönelme Durumu & окну' & о' кнам \\
Belirtme Durumu & окно' & о' кна \\
Araçlı Durum & окно' м & о' кнами \\
Kalma Durumu & окне' & о' кнах \\
\hline
\end{tabular}

3. Vurgunun yerinin değişkenliğinin ya da hareketliliğinin yol açtığı sorunlar yazım hataları ve gramer hataları;

a. Rusçada vurgunun sabit bir yerinin olmaması; köke, öneke, soneke, ismin hal ekine hatta bazen edata gelebilmesi sonucu ortaya çıkan yazım hatalarına örnek verecek olursak;

Vurgunun; -вы (вы́ йти , вы’́ копаться) - вице (ви́ це-чемпио' н , ви’́ це-губерна' тор) örneklerindeki gibi öneke gelmesi,

-овк /-ёвк (путё вка), -ура (литерату́ра), -ель (мете́ль, колыбе́ль, но ги́бель, ме́бель), -от(а) (доброта́), -изн(а) (новизна́), -б(а) (ходьба), -отн(я) (беготня') örneklerindeki gibi soneke gelmesi,

-по, -во, -в gibi edatlara gelmesi.

b. Zamanlara göre fiil çekimlerinde vurgunun yerinin değişmesi sonucu ortaya çıan yazım hatalarıyla oldukça sık karşılaştı̆̆ımızı görüyoruz. Bu tür hatalar gramer bilgisinde kalıcı yanlış öğrenmelere neden olabilmektedir.

Aşağıda altı çizili sözcüklerde (doğru olarak konan) vurguyu yanlış yere koyan öğrenci çekim eki almış bir şahıs zamiri ile fiil çekimini karıştırma hatasına düşmektedir. Gözlem grubumuzda bu tür hatalarla karşlaşma oranımız \% 73’tür.

$$
\begin{aligned}
& \text { Мою́ сестру' зову'т Лю́ да. } \\
& \text { Я } \underline{\text { мо ю } о м к и ' ~ п е ' ~ р е д ~ е д о ' ~ и ̆ ~}
\end{aligned}
$$

c. Bir sözcüğü diğerinden ayırt etmede yapılan yazım hataları.

Aşağıdaki örnekte sesteş iki sözcüğün ismin -in halinde çekime uğradıklarını ve ilk sözcükte vurgu kelimenin ilk hecesinde iken ikincisinde 2. hecesinde olduğunu görüyoruz. Böyle iki sözcüğün karıştırılma oranı ise oldukça yüksektir. Yaklaşı \%74.

\section{На две' ри за' мка}

\section{Нет замка'.}


Aşağıdaki örnekteki gibi tekerlemelerde ise, ek almamış bir isim ile ismin -in halinde çekilmiş başka bir ismin sesteş iki sözcükmüş gibi algılanabildiğini görüyoruz.

$$
\begin{aligned}
& \text { И у' тром бе' лка из белка' } \\
& \text { Ему' сбива' ет го' голь-мо' голь }
\end{aligned}
$$

Aşağıdaki örnekte ise tekil halde -in halinde çekimlenmiş bir kelime ile aynı kelimenin çoğul halinde vurgunun hareketliliğinden kaynaklı algı hatası olabileceğini görüyoruz.

$$
\text { Далеко от берега' - Бе́ рега красивы }
$$

4. Vurgunun yerinin hareketliliği sonucu ortaya çıkan hatalar.

Vurgunun yeri kimi kelimelerde hareketli olabilmektedir. Bu ismin tekil ya da çoğul haline, durum eklerine göre değişebilir.

Aşağıda vurgunun yerinin «hareketli» olmasına örnek teşkil eden bir tablo bulabilirsiniz.

\begin{tabular}{|lll|}
\hline İsmin Durum ekleri & Tekil & Çо̆̆ul \\
Yalın durum & голова' & го' ловы \\
Tamlayan Durumu & головы' & голо' в \\
Bënelme Durumu & голове' & голова' м \\
Araçlı Durum & го' лову & го' ловы \\
Kalma Durumu & $\begin{array}{l}\text { голово' й } \\
\text { голово ю }\end{array}$ & голова' ми \\
\hline
\end{tabular}

Tablodan takip edilebileceği üzere vurgunun yeri bazı kelimelerde hareketli olabilir ve yine yanlış öğrenmelerde, öğrencinin isimlerin çoğul durumlarını ismin tamlayan durumunun (-in hali) tekil haliyle karıştırdığı görülmüştür.

5. Ritmik modelleme sorunu:

Vurgunun yazımı öğretilirken ritmik modelleme yöntemi, kullanılan bir diğer yöntemdir. Şöyle gösterilir:

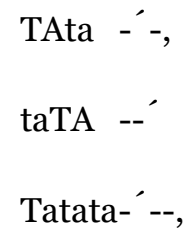


Learning erros caused by the faulty use of the stress sign of the Russian language which leads to learning errors made by learners who are native Turkish speakers / Z. Bakal (p. 196-206)

taTAta - - - -

$\ldots v b$.

Ritmik modelleme çizgileri fonetikten ayrı olarak verildiğinde öğrenci bunları Rusçadaki tonlama çizgileriyle;

---1 ?

-Это книга?

$-,---\backslash_{-} \cdot$

-Да, это книга.

Karıştırabilmekte, böylelikle hem kelime vurgusunu koymayı unutmakta, hem de cümlenin anlamını veren tonlama çizgilerini yanlış yorumlamaktadır. Ancak bu \%10 gibi oldukça düşük bir orandır.

\section{Otomatik sistemlerin sağladıkları ya da sağlayamadıkları}

Akıllara vurgunun doğru kullanımının öğretiminde teknoloji çağının getirilerinden faydalanılmakta mıdır sorusu gelebilir. Pratikte bu programlar mevcuttur ve iş yükünün çoğunu almakta yardımcıdır ancak henüz yeteri kadar gelişmiş değillerdir ve öğrenmeye katkı sunamamaktadırlar. Burada vurguyu otomatik yerleştiren bir programın, vurguyu edat yerine kelimenin ilk hecesine getiren yanlış bir uygulamasını görebilirsiniz.

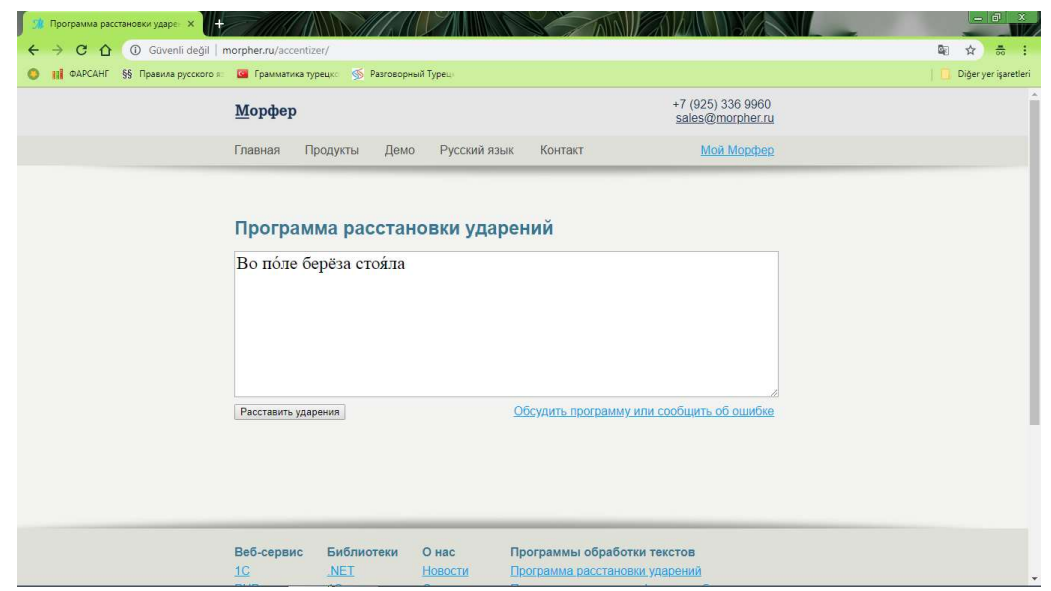

Bu, başka bir araştırmada kapsamlı bir şekilde ele alınması gereken bir konudur.

\section{Sonuç ve öneriler}

1. Alfabe sorunlarının giderilmesine yönelik öneriler.

Alfabeden kaynaklı sorunlara baktığımızda yazım hatalarının karşımıza çıktığını görüyoruz. Ek dilde yazma bir beceri alanıdır, uygulamaya ve pekiştirmeye ihtiyaç duyar. Yazma hatalarının giderilmesi yazma alıştırmalarının çokluğuna ve sürekliliğine bağlı olarak geliştirilebilir. Ancak yazma alıştırmalarına yönelik yeterli basılı kaynak ülkemizde olmadığından manuel olarak hazırlanan ders içi 
ve ders dışı etkinlikler yol gösterici olabilecektir. Bu etkinliklerin, Türk öğrenenlerin tespit edilmiş hataları üzerinde yoğunlaşmış olması, tekrara yönelik olması hedefler arasındadır.

2. Fonetik sorunların giderilmesine yönelik öneriler.

Vurgunun yazımının doğru öğrenilmesi Dil - Edebiyat ya da Çeviribilim dallarında öğrenim gören ve fonetik alfabe dersi alan öğrenenlerde yüksek oranda olurken, bu çalışmaya konu olan öğrenenlerde ve fonetik alfabe dersi görmeyenlerde \% 20 civarındadır.

Fonetik alfabeyi bilmeyen öğrenci hangi konuda çalıştı̆̆ının farkında olmayacaktır. Ses değişimlerini somut olarak algllayamayacak, edindiği bilgiler ezber seviyesinden öğrenme seviyesine geçemeyecektir.

Rusçadaki tonlama ile vurgunun karıştırılmasının önüne yine fonetik dersinin bu öğrenenlere ek ders olarak konulması ile geçilebilir.

3. Yazım hatalarının giderilmesine yönelik öneriler.

Yazım hataları bu hatalar içinde en önemli yere sahiptir çünkü yazımdan kaynaklı hatalar gramer hatalarına yol açabilmektedir. Yazım hatalarının giderilmesine yönelik olarak O. А Беженарь şöyle bir yöntem teklif eder; öğrenenlere önce sonu sert sessizle biten eril isimlerden ve sonu - a ile biten dişil isimlerden genellikle çoğulda “-ы” eki alanları öğretelim. Sonra biz kelimelerin tekilleri verelim ve öğrencilere çoğullarını söyletelim. 4-5 kelimeden sonra ping-pong prensibine göre bir çalışma yapalım; bir öğrenci tekil formu söylesin diğeri çoğul formu. Sonra tersi olsun. Bu pratik bize, ikili çalışma ile kelimelerin tekil, çoğul formlarında vurgunun yerinin anlaşılmasının kolaylığını gösterir. Sonra sınıfı ikiye bölüp, bu defa kelimeleri kendilerine bulduralım. Böylece rekabetten doğan öğrenme güdüsünü tetiklemiş oluruz.

A.A Поначевная ise Rusçada vurgu diye bir fenomen olduğunun öğrenenlere daha ilk dersten anlatılması gerektiğini savunur. Çeşitli yöntemler önerir: koro, grup çalışması, zincirleme gibi yöntemlerdir bunlar. Dikte ve kelime ezberlemeyi ek olarak alır.

Yazım hatalarının giderilmesi için öncelikle öğrenenlerin en çok vurgunun hareketliliğinden olmamasından kaynaklı hatalara düştükleri gözlemlenmiştir. Buna ders dışı etkinliklerin ciddiye alınmaması, öğrencinin verilen ödevleri yapmaması, tekrar çalışmalarında eksik kalması gibi faktörler de eşlik ettiği için bu süreç gereğinden uzun olmakta, bazen hata öğrenci tarafından olduğu gibi bırakılmakta, bu da yanlış öğrenme yüzünden öğrencinin ileri seviyeye geçmesine engel teşkil etmektedir. Bunların önüne geçmek için yazımda vurgusu hareketli kelime gruplarının en çok kullanılanlarıyla yapılan etkinlikler öğrenci için faydalı olacaktır.

Öğrenme etkinlikleri sırasında, öğrencilerin vurguyu yeni kelimeler ile beraber öğrendiklerinde doğru yere koydukları ancak dinleme etkinliklerinde karşılarına ilk kez çıkan kelimelerde hatalı yerlere koyabildikleri gözlemlenmiştir. Buna göre yazma etkinliğinin vurgu öğrenirken dinleme etkinliğinden daha etkili bir yöntem olabileceği görülür.

4. Gramer hatalarının giderilmesine yönelik öneriler.

Tek başına vuruğunun yanlış öğrenilmesinden kaynaklı gramer hatalarını çözmek için en başa bakmak yerinde olacaktır. Öğrenci el yazısı alfabeyi nasıl kullanacağını ve vurguyu çözememişse burada takılı 
Learning erros caused by the faulty use of the stress sign of the Russian language which leads to learning errors made by learners who are native Turkish speakers / Z. Bakal (p. 196-206)

kalacak, öğretilen gramer kuralını sindiremeyecektir. Gramer kuralları içinde kaybolmadan ve neyi yanlış anladığını bile anlayamadan öğrenci yazım aşamasında desteklemek gerekmektedir. Vurgu konusu gramer kurallarına girildiğinde verilecek bir konu olmayıp, başlangıç seviyesindeki öğrencinin ilk derslerine denk gelen bir yazım meselesidir.

\section{Kaynakça}

Балыхина T.М., Методика преподавания русского языка как неродного, нового (2007).

Беженарь О.А., Русское Ударение на начальном этапе обучения.

Издательство Ростовского Университета (1966), Орфография и пунктуация русского языка.

Поначевная А.А., Как объяснять ударения иностранным учащимся в курсе по рки на начальном этапе?

Шутова М.Н., Пособие по обучению русскому ударению.

Е.Б. Филимонова, Варианты ударений в современном русском языке.

О. Рогожина, Обучение аспектам русского языка как иностранного. Фонетика русской речи. Часть 6.

Новый орфографический словарь русского языка. 100 ооо слов. (2016)

Дорога в Россию 2. Элементарный уровень. А1. Учебник русского языка, (2014), Multilingual Yayınları.

Русский сезон. Учебник по русскому языку. Элементарный уровень (2017), Nüans Yayıncllık.

http://www.textologia.ru/russkiy/orfografia/?q=496

https://ru.wiktionary.org

https://pushkininstitute.ru/ 